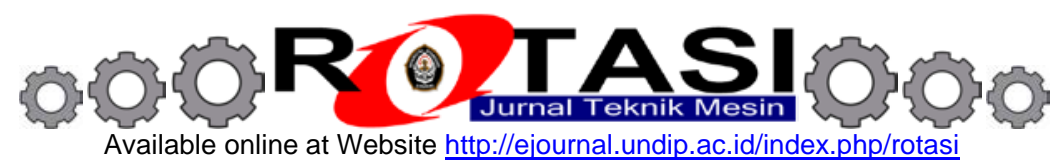

\title{
Analisa Perancangan Pada Produk Kaki Tiruan Atas Lutut tipe four bar linkage
}

\author{
Sugiyanto \\ Dosen Departemen Teknik Mesin, Fakultas Teknik, Universitas Diponegoro \\ Jl. Prof. Sudharto, SH., Tembalang-Semarang 50275, Telp. +62247460059 \\ Email: edt.sugiyanto@gmail.com
}

\begin{abstract}
Abstrak
Hilangnya sebagian alat gerak akan menyebabkan ketidakmampuan seseorang untuk melakukan aktivitas dalam derajat yang bervariasi. Untuk membantu kasus amputasi atas lutut diperlukan kaki tiruan atas lutut atau sering disebut sebagai above knee prosthesis (AKP) yang memiliki sendi lutut tiruan yang menyerupai sendi lutut asli. Produk AKP menghendaki fleksibilitas gerak, kenyamanan, fungsi kaki yang optimal dan kemudahan pengaturan. Artikel ini menunjukkan karakteristik perancangan AKP tipe four bar linkage yang dapat memenuhi ketiga fungsi tersebut. Kajian dilakukan terhadap penentuan dimensi berdasarkan analisa kinematis, distribusi beban dalam satu siklus gerak kaki (gait cylce) orang berjalan normal dan analisa tegangan von Mises menggunakan finite element method (FEM) pada beban statis dengan beban $1000 \mathrm{~N}$ pada sudut titik mati transfemoral prosthesis. Studi kasus yang dianalisa adalah produk AKP No. 3 dan 4 yang telah dibuat. Dari hasil kajian produk AKP No. 3 dan 4 tersebut digunakan untuk menentukan karakteristik perancangan.
\end{abstract}

Kata kunci: Above Knee Prosthesis, Transfemoral Prosthesis, Gait Cycle, Finite Element

\section{Pendahuluan}

Kaki tiruan adalah alat bantu berjalan yang dibutuhkan penyandang disabilitas kaki akibat proses amputasi atau disabilitas bawaan sejak lahir. Pada kasus amputasi di atas lutut diperlukan mekanisme pergerakan sendi lutut buatan yang baik agar pengguna merasakan kenyamanan saat menggunakannya. Selain itu produk kaki tiruan diharapkan mampu menahan beban tubuh saat digunakan untuk berjalan. Sejak Tahun 2013 Jurusan Teknik Mesin (JTM) UNDIP telah mengembangkan 4 jenis kaki tiruan, above knee prosthesis (AKP), untuk pasien dengan amputasi di atas lutut [14]. AKP jenis pertama didesain menggunakan batang tunggal dengan sendi penekuk hidrolik [1]. Jenis kedua didesain menggunakan batang tiga dengan sendi hidrolik [2]. Pada desain ketiga dan keempat, AKP menggunakan batang tunggal dengan sendi four bar linkage [3-4].

Desain AKP ketiga dan keempat menjadi model konsep dasar pengembangan produk. Desain AKP ketiga dan keempat ini menggunakan mekanisme sendi tiruan jenis polycentric knee atau four bar linkage knee. Kekurangan dari desain ketiga dan keempat yaitu kurang seimbang saat digunakan berdiri, belum bisa mengikuti gerakan gait cycle dengan baik, dan susunan middle linkage dan side linkage kurang memenuhi kriteria four bar linkage knee dan static alignment above knee prosthesis. Dengan demikian diperlukan beberapa kajian untuk meminimalkan sejumlah kekurangan tersebut, yang meliputi analisa kinematis four bar linkage yang mengalami perubahan posisi ketika melakukan gerak gait cycle, distribusi beban dalam satu siklus gerak kaki (gait cylce) orang berjalan normal dan analisa tegangan von Mises menggunakan finite element method (FEM) pada beban statis dengan beban $1000 \mathrm{~N}$ pada sudut titik mati transfemoral prosthesis. Studi kasus yang dianalisa adalah produk AKP no 3 dan 4 yang telah dibuat. Dari hasil kajian produk AKP no 3 dan 4 tersebut digunakan untuk menentukan karakteristik perancangan.

\section{Material dan metodologi}

Secara umum metode yang digunakan pada kajian ini adalah melakukan analisa kinematis, distribusi beban dalam satu siklus gerak kaki (gait cylce) orang berjalan normal dan analisa tegangan von Mises menggunakan FEM pada beban statis dengan beban $1000 \mathrm{~N}$ pada sudut titik mati transfemoral prosthesis. Analisa tersebut didasarkan pada produk AKP No. 3 dan 4, dengan bantuan software Solidworks.

\section{Hasil dan pembahasan}

Analisa kinematis merupakan analisa gerak yang dapat dilakukan dari produk kaki tiruan tipe four bar linkage untuk mendapatkan dimensi (panjang) dan posisi sumbu gerak. Analisa kinematis ini harus sesuai dengan kondisi gait cylce orang berjalan normal. Pemodelan 3D diperlukan untuk menganalisis pergerakan produk AKP UNDIP berdasarkan data knee flexion angle gait cycle, dalam hal ini geometri yang didapat dari proses perancangan kemudian kita modelkan dengan software CAD (Computer Aided Design) SolidWorks. Gambar 1 menunjukkan analisa kinematis yang dilakukan terhadap beberapa dimensi AKP. 


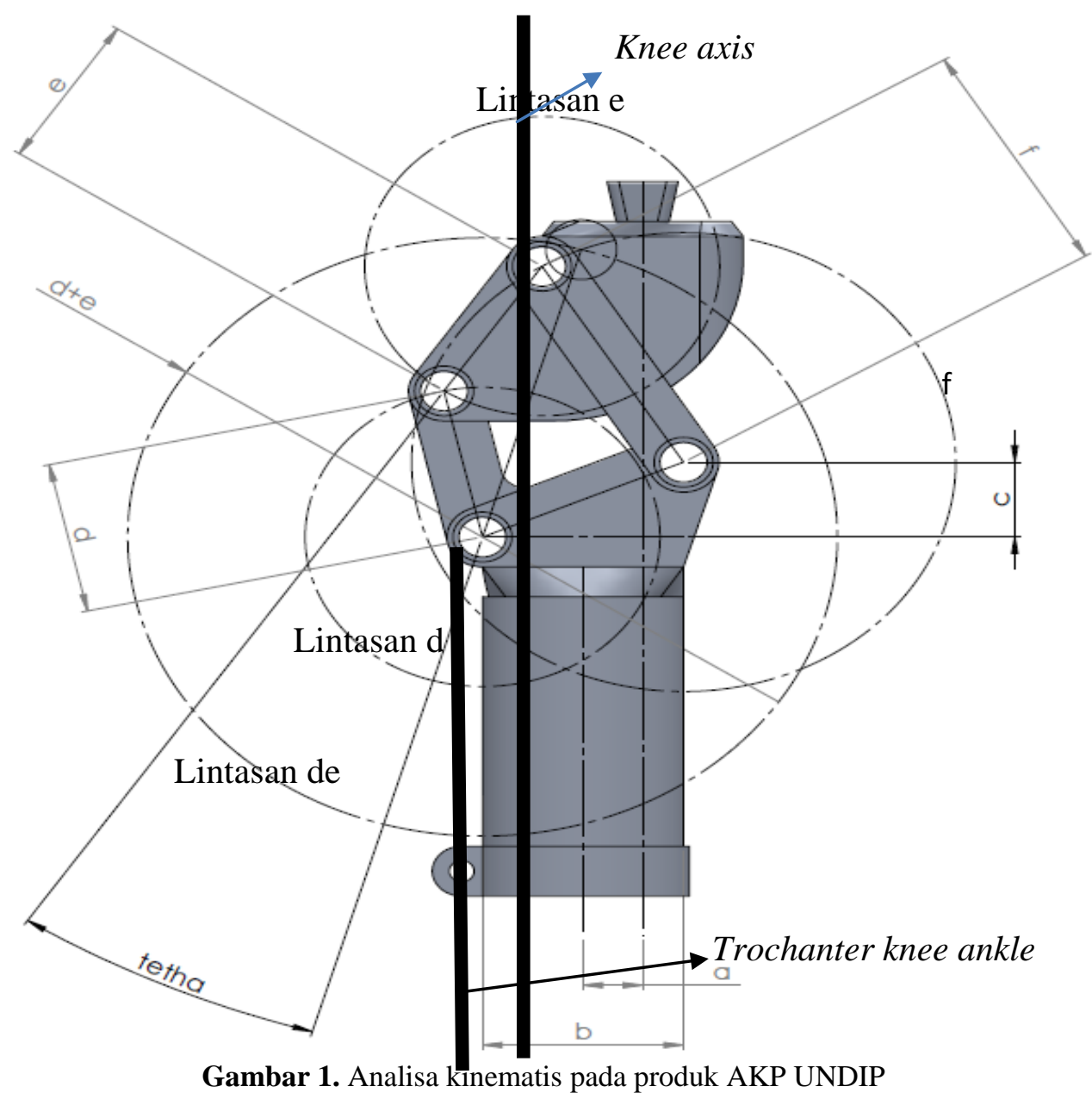

Keterangan Gambar 1:

$\mathrm{a}=$ jarak antara TKA (trochanter knee ankle) dengan knee axis besarnya adalah $10 \mathrm{~mm}$

$\mathrm{b}=$ diameter luar komponen betis, besarnya adalah $34 \mathrm{~mm}$ dan diameter dalam $30 \mathrm{~mm}$.

$\mathrm{c} \quad=\quad$ tinggi antara pin $\mathrm{f}$ dengan pin $\mathrm{d}$. Ketinggian pin $14 \mathrm{~mm}$.

$\mathrm{d}=$ Middle Link, panjangnya adalah $30 \mathrm{~mm}$.

$\mathrm{e} \quad=\quad$ Panjang $27 \mathrm{~mm}$.

$\mathrm{f} \quad=$ Side link, panjang $46 \mathrm{~mm}$.

$\theta=$ besar sudut tetha $\theta>15^{\circ}$

Gerakan lutut yang normal pada Gambar 1 adalah gerakan kompleks yang terdiri dari mengayun (Rocking), meluncur (Gliding) dan rotasi (Axial Rotation). Titik pusat sesaat/ICR ditentukan untuk setiap peningkatan fleksi bergerak ke posterior dalam pola spiral. Pusat sesaat (instant centres) atau ICR ini tidak tetap dalam satu posisi seperti pada sendi engsel sederhana seperti Single-Axial, melainkan menggambarkan sebuah beberapa pusat atau jalur polisentris. Gambar 2 menunjukkan pola perubahan titik pusat sesaat produk UNDIP yang mempunyai kemiripan dengan pola spiral pada gerakan lutut normal.

Gait cycle merupakan siklus gerakan manusia melakukan gerakan berjalan. Siklus berjalan ini mempunyai 8 fase yaitu initial contact, loading respons, mid stance, terminal stance, pre-swing, initial swing, mid swing dan terminal swing. Gerakan sendi lutut tiruan harus sealami mungkin agar dapat mengikuti fleksi dan ekstensi lutut saat gait cycle. Gambar 3 dan Gambar 4 menunjukkan perbandingan Knee Flexion Angle dengan pergerakan produk AKP UNDIP 3 dan 4.

Berdasarkan data yang ditunjukkan pada Gambar 3 dan Gambar 4, diperoleh penyimpangan gerakan selama siklus gait cycle untuk produk AKP UNDIP 3 sebesar 38,8 \% dan produk AKP UNDIP 4 sebesar 38,8\%. 


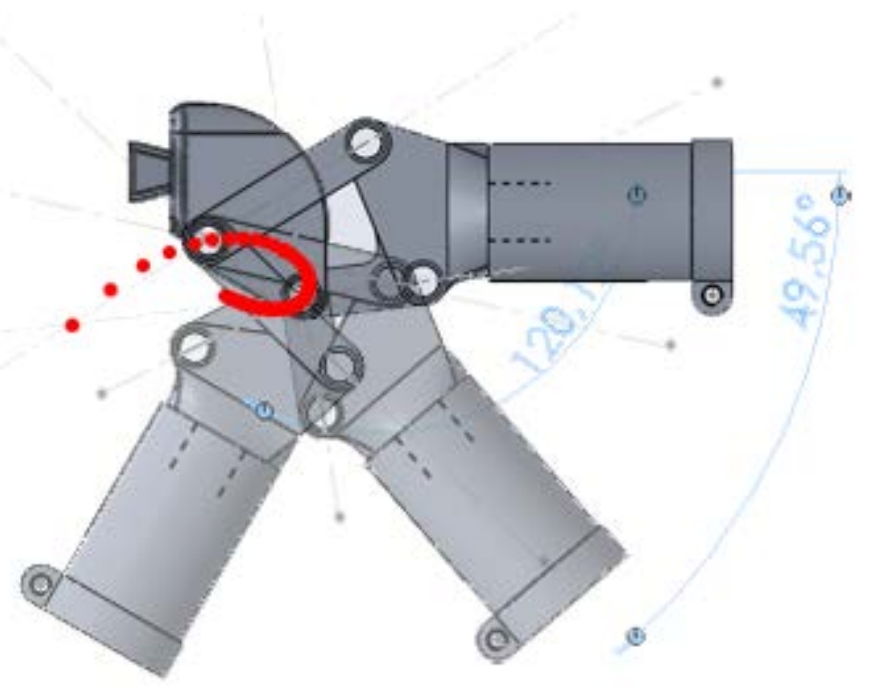

Gambar 2. Pola pergerakan kaki palsu produk UNDIP

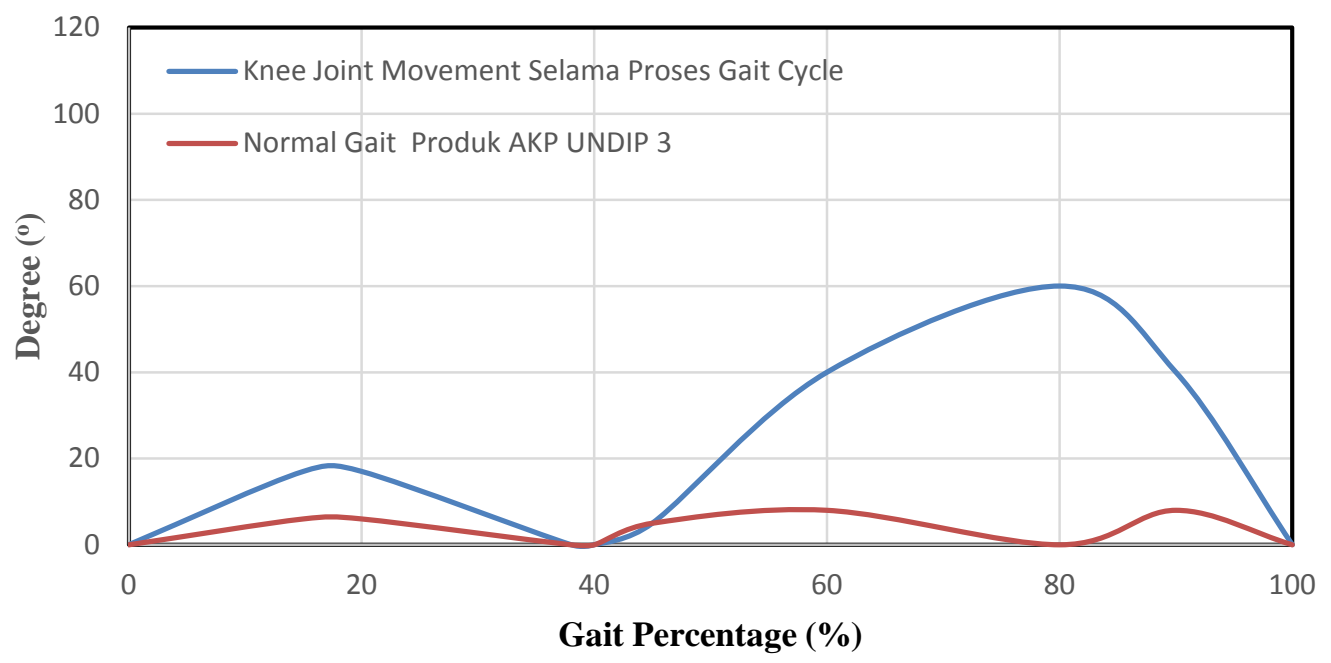

Gambar 3. Grafik perbandingan gerak produk AKP UNDIP 3 dan grafik Knee Flexion Angle

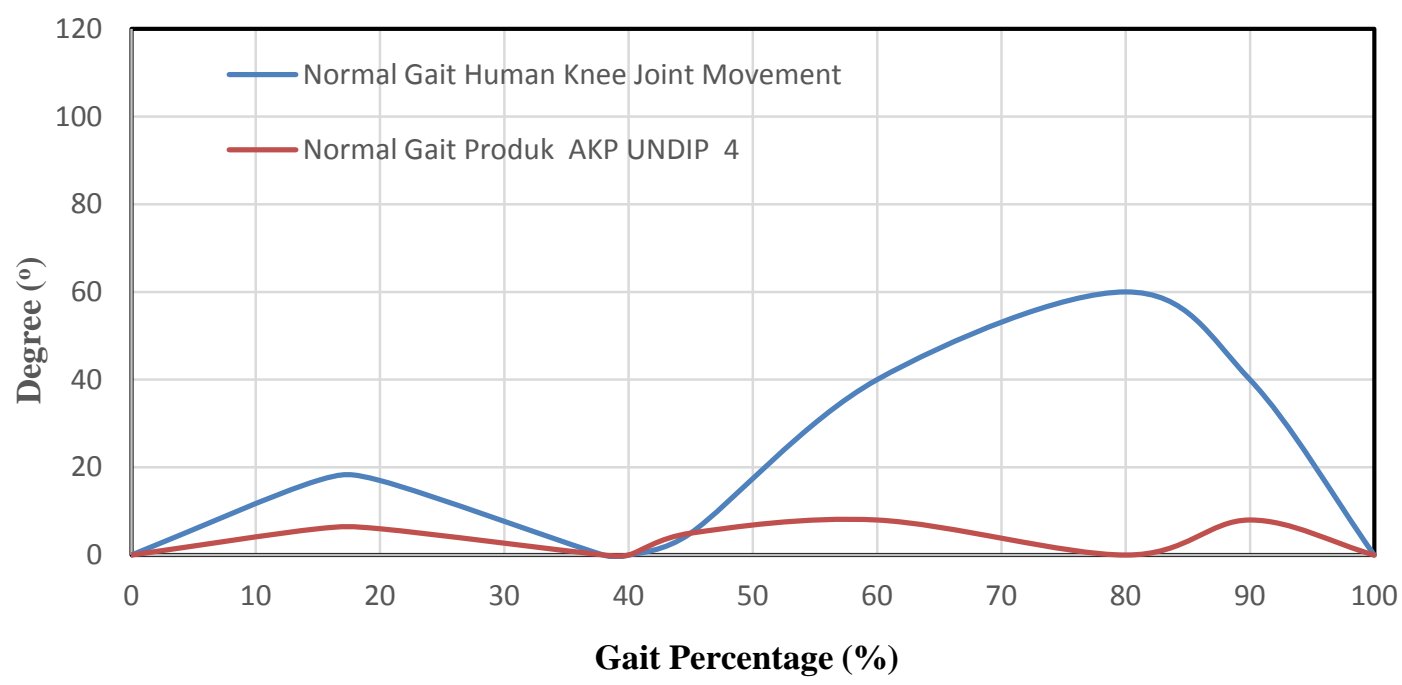

Gambar 4. Grafik perbandingan gerak produk AKP UNDIP 4 dan grafik Knee Flexion Angle 


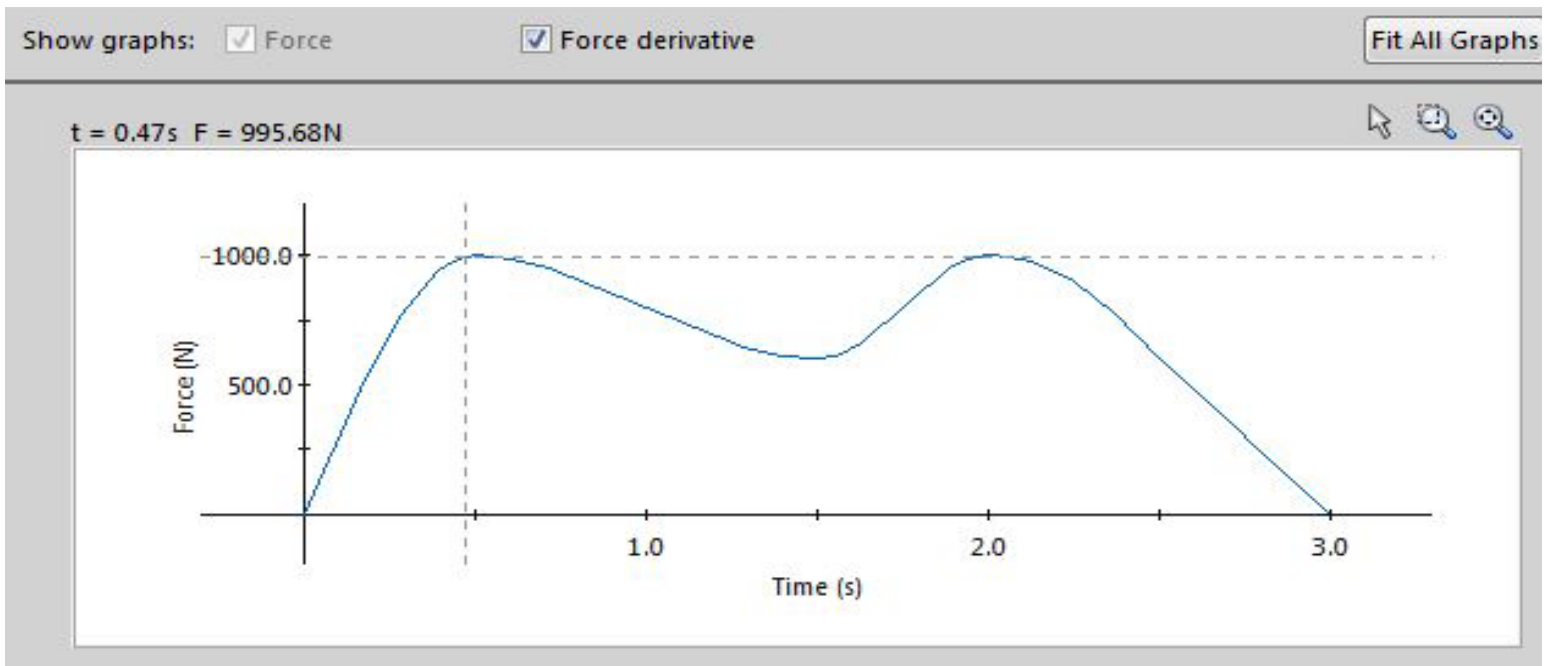

Gambar 5. Grafik pembebanan [6]

Distribusi beban dalam satu siklus gait cycle digunakan untuk arah beban sesuai dengan posisi kaki tiruan pada saat tersebut. Berdasarkan data pada Gambar 5 didapatkan posisi beban maksimum terjadi pada 15\% gait cycle atau

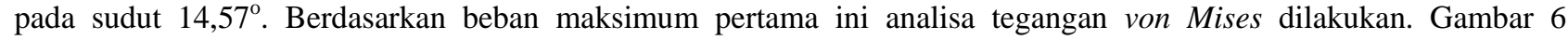
menunjukkan distribusi tegangan von Mises dengan tegangan maksimum sebesar 98,12MPa

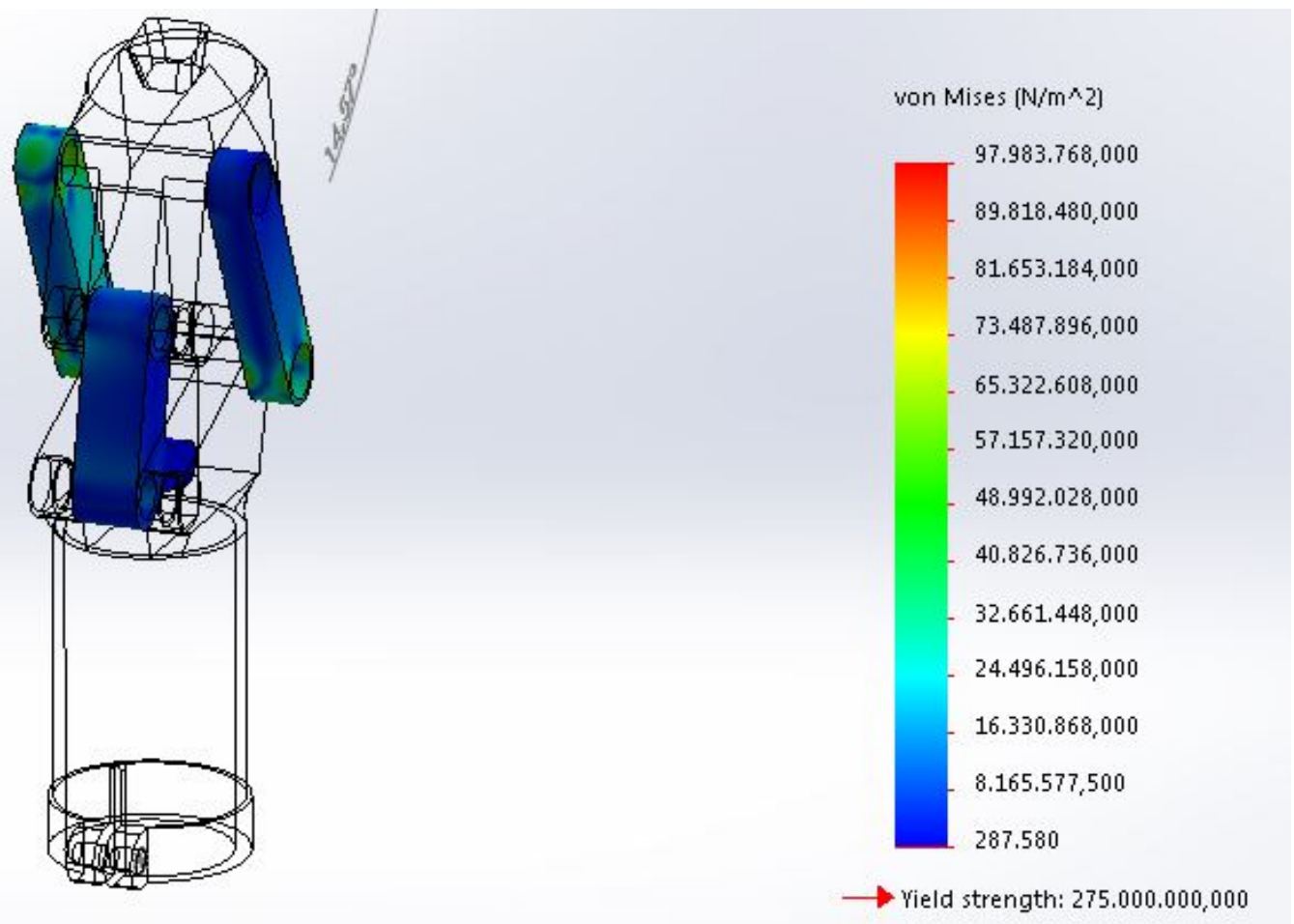

Gambar 6. Tegangan von Mises pada sudut $14,57^{0}$

Dari uraian diatas terlihat bahwa untuk memenuhi kriteria fleksibilitas gerak, kenyamanan, fungsi kaki yang optimal dan kemudahan pengaturan pada produk AKP memerlukan analisa kinematis, distribusi beban dalam satu siklus gerak kaki (gait cylce) orang berjalan normal dan analisa tegangan von Mises menggunakan finite element methode (FEM) pada beban statis dengan beban $1000 \mathrm{~N}$ pada sudut titik mati transfemoral prosthesis.

\section{Kesimpulan}

Guna memenuhi kriteria perancangan pada produk kaki tiruan atas lutut memerlukan sejumlah analisa. Dari analisa yang dilakukan, produk AKP UNDIP 3 dan 4 belum menunjukkan hasil yang baik, hal ini ditunjukkan adanya simpangan gerakan selama siklus gait cycle untuk produk AKP UNDIP 3 sebesar 38,8 \% dan produk AKP UNDIP 4 sebesar $38,8 \%$. 


\section{Referensi}

[1] A.R. Ismawan, Perancangan dan Analisa Above Knee Prosthetic untuk Pasien Amputasi Kaki di Atas Lutut dengan Desain Fleksibel dan Ergonomis, Jurusan Teknik Mesin UNDIP, Tugas Akhir S-1 UNDIP, 2013.

[2] D. Bactiar, Rancang Bangun Biomekanisme pada Sendi Prostesa untuk Pasien Amputasi Atas Lutut dengan Desain Ergonomis dan Fleksibel, Jurusan Teknik Mesin UNDIP, Thesis S-2, UNDIP, 2014.

[3] A. Fauzilhaq, O.G. Keloko, Proses Perancangan dan Pembuatan Above Knee Prosthethic, Jurusan Teknik Mesin UNDIP, Tugas Perancangan, UNDIP, 2014.

[4] M. Dzulfikar, Analisa Gait Cycle dan Beban Statis Produk Kaki Tiruan Atas Lutut (Above Knee Prosthethic) Menggunakan Metode Elemen Hingga, Jurusan Teknik Mesin UNDIP, Jurnal Momentum, accepted, 2015.

[5] M.W Whittle, Gait Analysis an Introduction, $4^{\text {th }}$ Ed., Butterworth Heinemann Elsevier, Philadelphia, USA. 2007.

[6] Oh, S.E., Choi, A. and Mun, J.H., 2013. Prediction of ground reaction forces during gait based on kinematics and a neural network model. Journal of biomechanics, 46(14). 